\title{
Preparation of Thermosetting Polystyrene Insulation Board
}

\author{
Guo-Zhong LU ${ }^{1, a}$, Xiu-Juan DING ${ }^{1, b, *}$, Jia-Yang ZHANG ${ }^{1, c}$, Yu DENG ${ }^{1, d}$ and \\ Cong-Cong $\mathrm{LI}^{1, \mathrm{e}}$
}

${ }^{1}$ Beijing Building Materials Academy of Sciences Research, State Key Laboratory of Solid Waste Reuse for Building Materials, Beijing Passive Low-energy Consumption Architectural Engineering

Technology Research Center, Beijing 100041, China

adingxiujuanlove@126.com

*Corresponding author

Keywords: Polystyrene, Thermoplastic, Thermoset, Flame retardant coating.

\begin{abstract}
To change the combustion performance of polystyrene plates, the thermosetting phenolic resin $/ \mathrm{Al}(\mathrm{OH})_{3}$ solution retardant, a method of flame retardant coating was used. By the analysis of the main preparation process, a kind of thermosetting polystyrene insulation board was made, and the problem between flame retardant and insulation was solved. The test results showed that it would not melt or shrink when the coated polystyrene plates burning, only carbonized on the surface. All the performance indicators meet to the standards. The performance of heat conductivity and combustion significantly improved.
\end{abstract}

\section{Introduction}

PS insulation board has been widely used in China's exterior wall insulation system due to its good insulation properties, low cost, mature construction technology and good stability [1-3]. But with improvement of structural fire safety requirements, traditional PS insulation board shrinks, melts and drops and its drops has second ignition property, is greatly restricted in exterior wall insulation system of a building due to its thermoplasticity [4-5]. Therefore, improving the combustion performance of PS insulation board, especially the thermoplasticity is an important way that PS insulation board is re-recognized by the market. The work is to improve the preparation process of traditional molded PS insulation board, coat the pre-foamed PS particles with organic/inorganic composite flame retardant material so that the combustibility of PS foam becomes from combustible thermoplasticity to flame-resisting thermosetting property, the combustibility of traditional PS insulation board is greatly improved based on the principle of fire retardation by means of coating, and to conduct test analysis to the performance of the improved molded PS foam board modified by phenolic resin.

\section{Experiment}

\section{Raw Materials}

Expandable PS, size: 0.7 1.1 mm, expanding times: 60 by Tianjin Xinlongqiao En-gineering Plastics Co., Ltd. Thermosetting phenolic resin by Jinan Yihong Chemical Co., Ltd. Flame retardant, $\mathrm{Al}(\mathrm{OH})_{3}$, size $12.0 \sim 14.0 \mu \mathrm{m}$ by Hefei Zhongke Flame-Retardant New Material Co., Ltd. Curing agent: Prepared by p-toluenesulfonic acid, $\mathrm{H}_{3} \mathrm{PO}_{4}$ and $\mathrm{HCl}$ in proportion.

\section{Instruments and Equipment}

JF-3 oxygen index tester by Jiang ning Nanjing Analytical Instrument Co., Ltd.; im-DRY3001 heat conductivity tester by Tianjin Impal Science and Technology Development Co., Ltd.; PENTAPYC 5200e automatic opening and closing tester by Quantachrome; S-3400 scanning electronic microscope by Hitachi. 


\section{Test Methods}

The density is tested according to GB/T 6343-2009; the heat conductivity is tested according to GB/T 10294-2008; the board-perpendicular tensile strength is tested according to JG149-2003; the compressive strength is tested according to GB/T 8813-2008; the dimensional stability is tested according to GB/T 8811-2008; the water absorption is tested according to GB/T 8810-2005; the oxygen index is tested according to GB/T 2406.1-2008; and the combustibility level is tested according to GB 8624-2012.

\section{Technical Route}

Molded polystyrene foam board modified by phenolic resin is a micro compound system formed by means of enveloping and drying the pre-foamed PS particles and modified phenolic resin so as to realize the insulating property of material and surface fire retardation, non-melting and non-dropping properties and achieve the purpose of fire protection and thermal insulation. Preparation of molded polystyrene foam board technical route is shown as Fig.1.

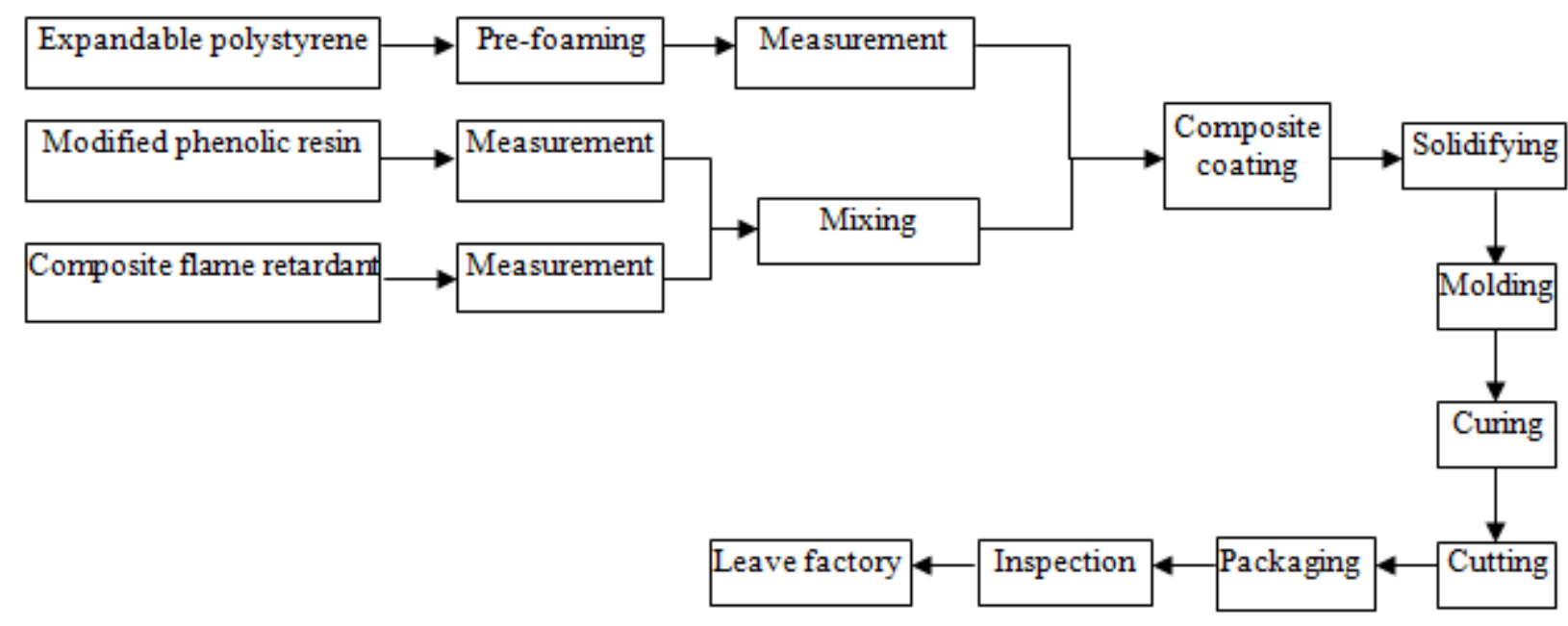

Fig.1. The preparation of molded polystyrene foam board modified by phenolic resin.

Composite flame retardant is made up of modified phenolic resin and $\mathrm{Al}(\mathrm{OH})_{3}$. Thermo-setting phenolic resin/ $\mathrm{Al}(\mathrm{OH})_{3}$ is evenly coated on the surface of PS particles in the process of coating, the overall structure of the materials is optimized in the process of experiment to form an optimal formula through experimental contrast, effectively improving the fire retardation property of flame retardant materials and ensuring the thermal insulation effect of the material.

\section{Study on Optimization of Main Preparation Process}

In the process of expandable PS bead foaming, the processing parameters (pressure, temperature, time, etc.) of expandable PS beads directly affect the structure and properties of foam. This work is mainly to discuss the parameter control of the pre-foaming and curing process in combination with the production experience in the production process. At the same time, coating process by thermosetting phenolic resin/ $\mathrm{Al}(\mathrm{OH})_{3}$ solution retardant plays a crucial role in the preparation of modified molded PS foam board.

\section{Pre-foaming Process}

In the experiment, the steam is used for pre-foaming to make the expandable PS particles expand to a certain extent. In pre-foaming process, the steam constantly penetrates into the bubbles, the pressure in the bubbles increase constantly, and the bead volume is also increasing. The steam pressure and 
heating time must be properly controlled during production, otherwise, the foamed particles shrink due to overheat is cooled. Meanwhile, the too high multiplying factor shall be avoided to prevent formed piece shrinking and deforming. It is appropriate to control the pressure of the prefoamed bubbles within $0.15 \sim 0.20 \mathrm{MPa}$, and the pre-foaming time within $180 \sim 200 \mathrm{~s}$, and ideal expandable PS particles can be got. Expandable PS particle packing density shall be measured from time to time during actual operation to make proper fine-tuning.

\section{Curing process Parameter Control}

After pre-foaming, vacuum will be generated in expandable PS particles, and there will be water on the surface, which do not conform to the requirements of molding. The purpose of curing is to make the air access to the particles to volatilize the foaming agent, and dry the surface moisture of the particles. Bubbles will become vacuum in the process of curing. At the same time, the pressure in the bubbles keeps balance with the pressure outside so that the pre-foamed beads are resilient. Curing cycle depends on the bead density, degree of humidity and temperature of the storage environment. The best curing time is 16 to $24 \mathrm{~h}$. Curing temperature is an important control factor. The best curing temperature for expandable PS beads is $20 \sim 25{ }^{\circ} \mathrm{C}$. When the curing temperature is $18 \sim 22{ }^{\circ} \mathrm{C}$, the ambient air penetrates into the bubbles, and the pentane in bubbles basically do not diffuse outside; when the temperature is higher than $22{ }^{\circ} \mathrm{C}$, the air infiltration rate is accelerated, and the pentane in the bubbles diffuse outside and get lost.

\section{Coating by Thermosetting Phenolic Resin/Al(OH) $)_{3}$ Solution Retardant}

Foam bead coating technology should ensure that each foam bead shall form an in-dependent blocking layer. Blocking layer has good flame retardant effect, can reduce transmission of heat, combustible material and oxygen, and will not melt and drop even if under the continuous action of ambient strong fire. When $\mathrm{Al}(\mathrm{OH})_{3}$ powder is mixed in phenolic resin, the solid beads become moist first, and disperse under the effect of stirring. The mixing and stirring speed of thermosetting phenolic resin/ $\mathrm{Al}(\mathrm{OH})_{3}$ should depend on the actual working temperature and dynamic viscosity of phenolic resin. After identifying the mixing and stirring speed, stir and mix at a stirring speed higher than the critical mixing speed to make the thermosetting phenolic resin/ $\mathrm{Al}(\mathrm{OH})_{3}$ solution retardant, and then finish coating.

\section{Results and Discussion}

\section{Analysis on the Microstructure of Modified PS Particles}

We can know from Fig. 2 that the coating layer is jelly, mainly is the material containing carbon. After coating process, each PS particle is independently coated with the flame retardant material, and the coating layer is relatively uniform. Good coating effect makes the PS insulation board of good flame retardant performance, the use of thermosetting phenolic resin/ $\mathrm{Al}(\mathrm{OH})_{3}$ solution retardant ensures the flame retardant properties of thermosetting PS foam. 


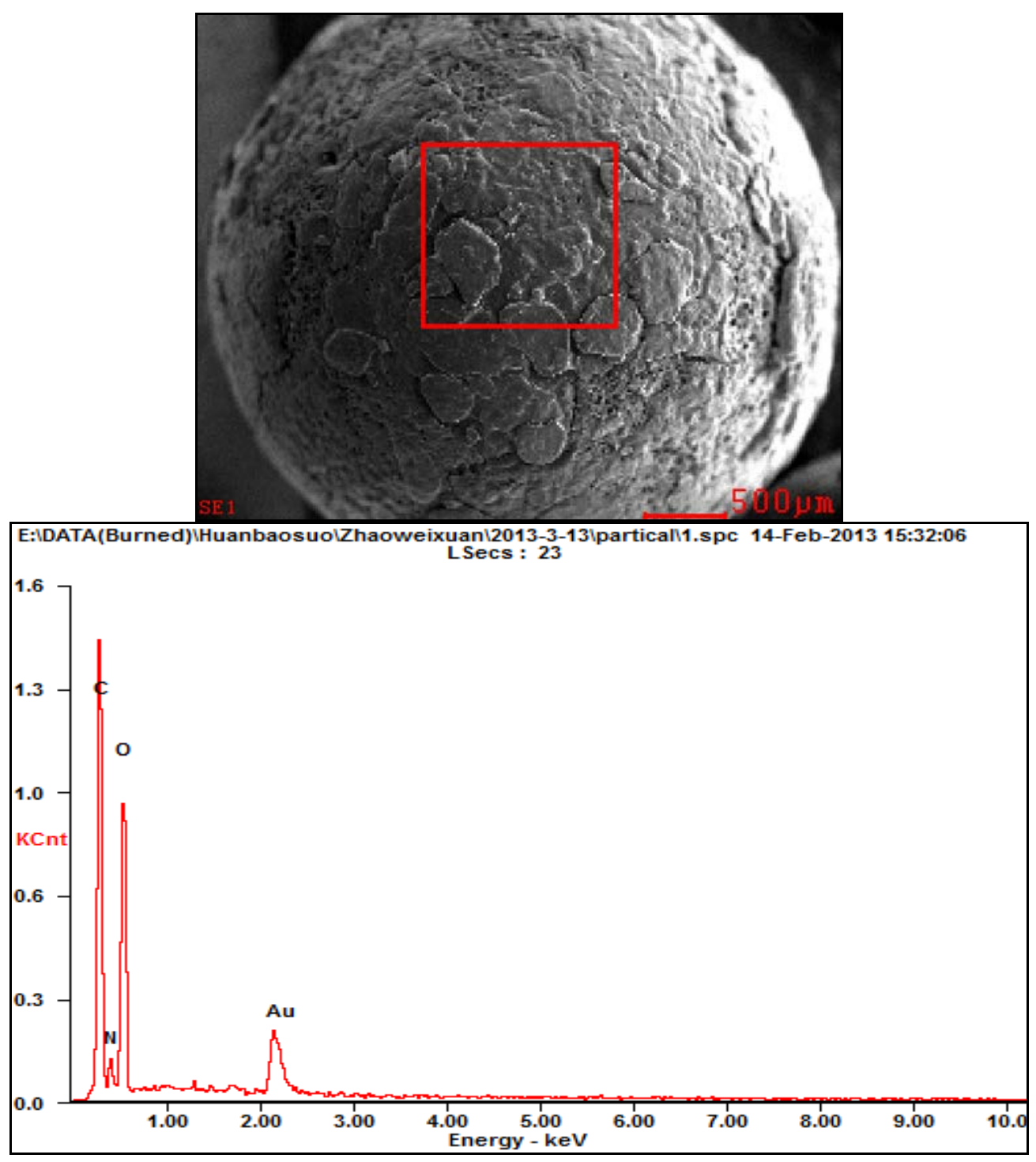

Fig.2. SEM photograph and SEM energy spectrum analysis of the modified polystyrene particles.

\section{Influence of Phenolic Resin and $\mathrm{Al}(\mathrm{OH})_{3}$ Content to the Heat Conductivity of Foam Board}

Test results on heat conductivity of modified PS foam insulation board of different $\mathrm{Al}(\mathrm{OH})_{3}$ content (its mass is $20 \mathrm{~g}$ relative to PS composite bead) under different phenolic resin content (its mass is $20 \mathrm{~g}$ relative to PS compound bead) are shown in table 1. It can be seen from Tab.1 and 3 that under the condition that the mass ratio of compound beads to the flame resistant fluid below 20:120, the heat conductivity of the molded PS foam board modified by phenolic resin increases as the phenolic resin content increasing when the $\mathrm{Al}(\mathrm{OH})_{3}$ content is the same. It shows that thermosetting phenolic resin can significantly improve the heat conductivity of the material when adopting the foam bead coating technology for fire retardant treatment. This may be because the heat conductivity increases after the thermosetting phenolic resin foaming. 
Tab.1 The heat conductivity of phenolic resin and $\mathrm{Al}(\mathrm{OH})_{3}$ with different content $\mathrm{W} /(\mathrm{m} \cdot \mathrm{K})$

\begin{tabular}{lllllll}
\hline \multirow{2}{*}{$\begin{array}{l}\mathrm{Al}(\mathrm{OH})_{3} \\
\text { content/g }\end{array}$} & \multicolumn{6}{l}{ Content of phenolic resin/g } \\
\cline { 2 - 7 } & 50 & 60 & 70 & 80 & 90 & 100 \\
\hline 0 & 0.0326 & 0.0332 & 0.0337 & 0.0341 & 0.0345 & 0.0351 \\
5 & 0.0335 & 0.0335 & 0.0338 & 0.0343 & 0.0346 & 0.0352 \\
10 & 0.0343 & 0.0344 & 0.0346 & 0.0348 & 0.0350 & 0.0353 \\
15 & 0.0348 & 0.0349 & 0.0352 & 0.0354 & 0.0354 & 0.0357 \\
20 & 0.0355 & 0.0357 & 0.0357 & 0.0359 & 0.0362 & 0.0365 \\
\hline
\end{tabular}

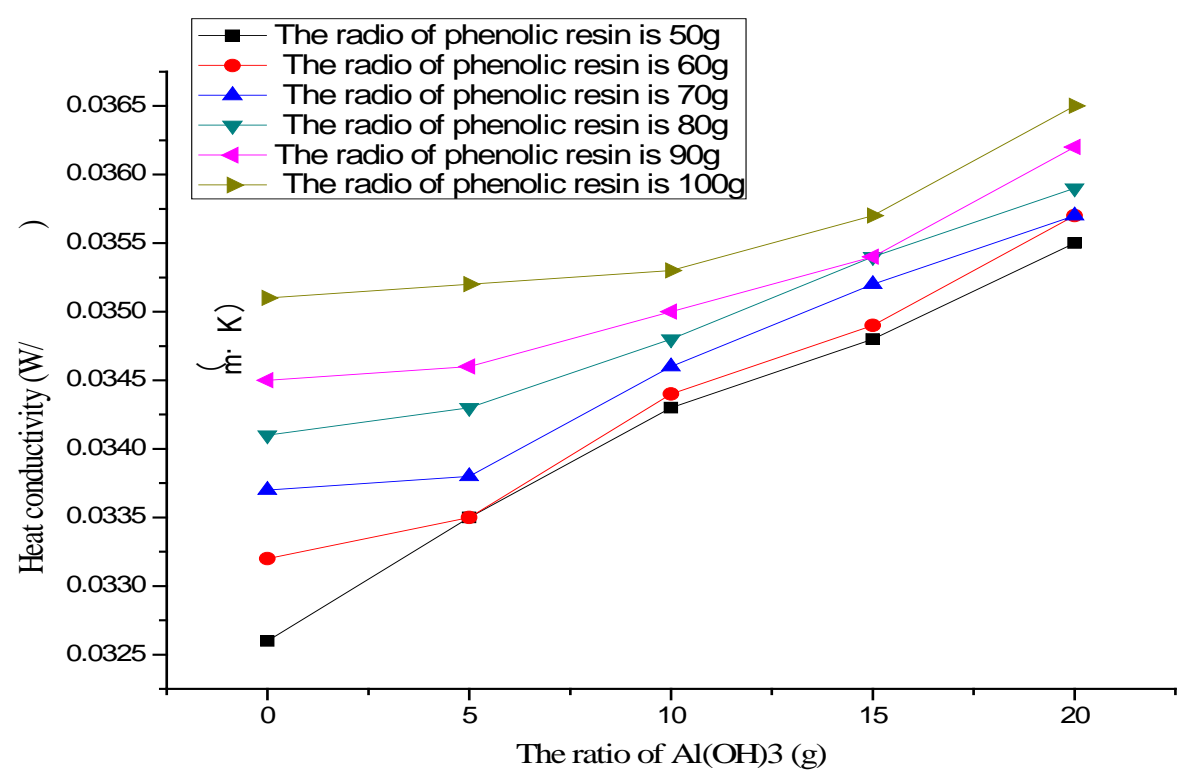

Fig.3. Influence of phenolic resin and $\mathrm{Al}(\mathrm{OH})_{3}$ content to the heat conductivity of foam board.

\section{Influence of pHenolic Resin and $\mathrm{Al}(\mathrm{OH})_{3}$ Content to the Oxygen Index of Foam Board}

Test results on oxygen index of modified PS foam insulation board of different $\mathrm{Al}(\mathrm{OH})_{3}$ content (its mass is $20 \mathrm{~g}$ relative to PS composite bead) under different phenolic resin content (its mass is $20 \mathrm{~g}$ relative to PS compound bead) are shown in table 2.

Tab.2 The oxygen index of phenolic resin and $\mathrm{Al}(\mathrm{OH})_{3}$ with different content $\mathrm{W} /(\mathrm{m} \cdot \mathrm{K})$

\begin{tabular}{lllllll}
\hline \multirow{2}{*}{$\begin{array}{l}\mathrm{Al}(\mathrm{OH})_{3} \\
\text { content/g }\end{array}$} & \multicolumn{6}{l}{ Content of phenolic resin/g } \\
\cline { 2 - 7 } & 50 & 60 & 70 & 80 & 90 & 100 \\
\hline 0 & 22.2 & 23.9 & 25.2 & 26.5 & 27.4 & 28.3 \\
5 & 23.7 & 26.6 & 27.5 & 29.1 & 30.4 & 30.6 \\
10 & 25.6 & 28.6 & 30.1 & 31.4 & 32.6 & 32.8 \\
15 & 28.1 & 30.4 & 32.5 & 33.4 & 34.6 & 34.8 \\
20 & 21.2 & 22.5 & 24.4 & 25.5 & 26.7 & 26.9 \\
\hline
\end{tabular}


Control the mass ratio of compound beads to the flame resistant fluid below 20:120, and observe the effect of the content of $\mathrm{Al}(\mathrm{OH})_{3}$ on the oxygen index of foam insulation board when the phenolic resin content is different. It can be seen from Fig. 4 that when the phenolic resin mass ratio is the same, the oxygen index of the insulation material increases constantly as the $\mathrm{Al}(\mathrm{OH})_{3}$ content increasing, and when the content of $\mathrm{Al}(\mathrm{OH})_{3}$ is more than a certain value, the oxygen index will no longer increase, but decreases sharply. It shows that $\mathrm{Al}(\mathrm{OH})_{3}$ content shall be controlled within a certain range when adopting foam bead coating technology for flame retardant treatment, and the oxygen index of modified molded PS foam board can be effectively improved. When the content of $\mathrm{Al}(\mathrm{OH})_{3}$ is the same, the oxygen index will increase with the increase of phenolic resin content, indicating that phenolic resin can to a certain extent, improve the oxygen index of insulation board. Combined the heat conductivity with the oxygen index, the phenolic resin content and the best $\mathrm{Al}(\mathrm{OH})_{3}$ content are 100 and $15 \mathrm{~g}$ respectively.

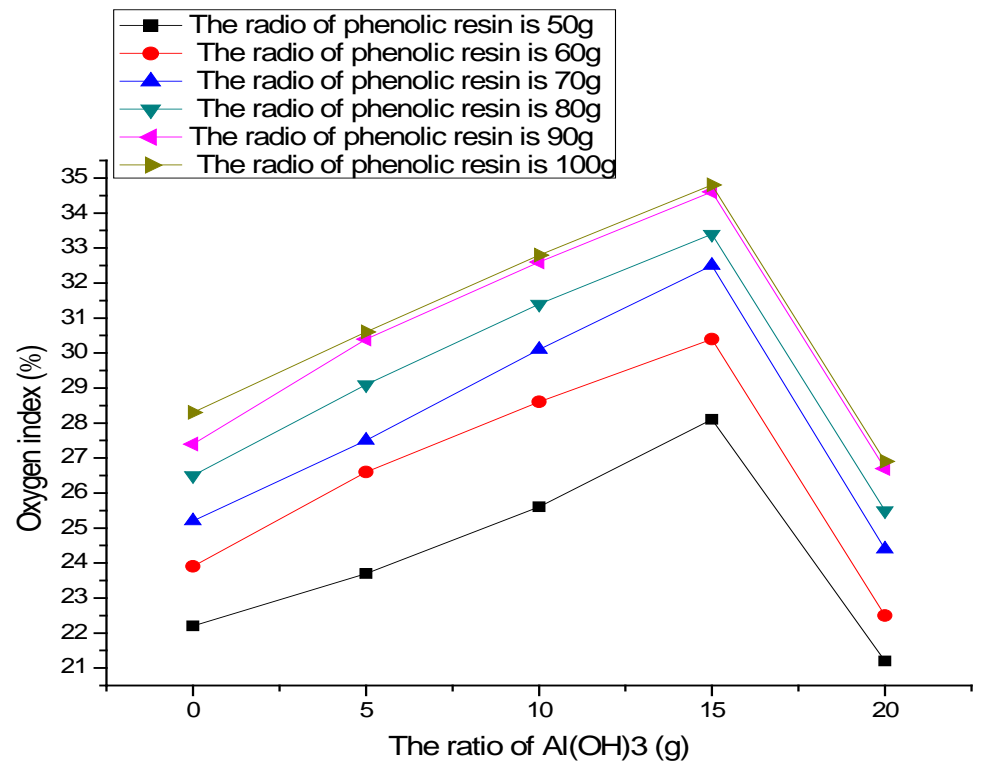

Fig.4. Influence of phenolic resin and $\mathrm{Al}(\mathrm{OH})_{3}$ content to the oxygen index of foam board.

\section{Flammability Testing of Molded Polystyrene Foam Board Modified by Phenolic Resin}

Jet $1700^{\circ} \mathrm{C}$ flame with a spray gun for $5 \mathrm{~min}$, record the phenomena generated during the combustion, contrast the effect before and after the combustion of the insulation board, and characterize the flame retardant property of the insulation board. It can be seen from Fig. 5 that coated PS foam board does not melt and drop after burning, but the carbonizes on the surface, and thermosetting combustibility is realized, the combustibility of anti-flaming coated PS insulation board becomes from thermoplastic to thermosetting; and the problem of inter-restriction between the flame retardant property and the heat insulation property of the insulation board is solved by preparing thermosetting phenolic resin $/ \mathrm{Al}(\mathrm{OH})_{3}$ flame retardant.
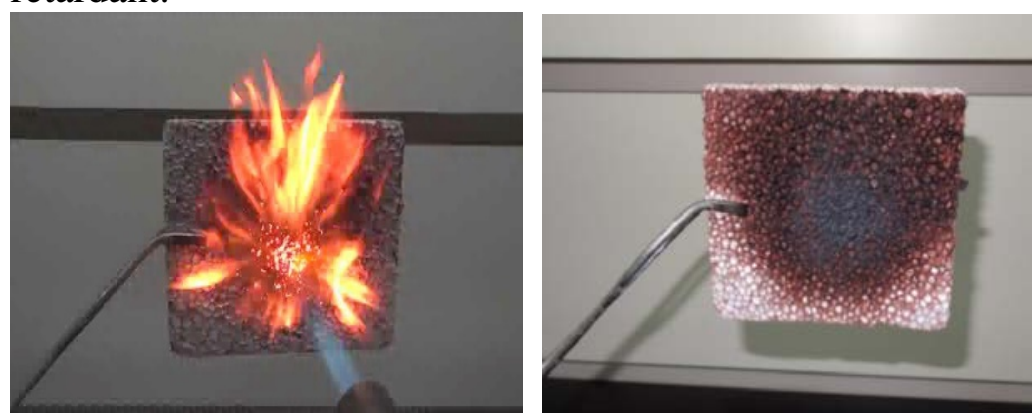
Fig.5. Flammability testing of molded polystyrene foam board modified by phenolic resin.

\section{Comprehensive Performance Test of Thermoset Polystyrene Foam Insulation Board}

It can be seen from Tab.3 that the combustibility of the molded polystyrene foam board modified by phenolic resin after flame retardant coating can reach level B1, and the calorific value is $20.3 \mathrm{MJ} / \mathrm{kg}$, far less than that of ordinary PS (46 MJ/kg); thermal insulation coefficient is less than $0.036 \mathrm{~W} /(\mathrm{m} \bullet \mathrm{K})$, is better than that of ordinary PS insulation board [heat conductivity is $0.039 \mathrm{~W} /(\mathrm{m} \cdot \mathrm{K})$ ].

Tab.3 Comprehensive performance test of thermoset polystyrene foam insulation board

\begin{tabular}{lll}
\hline Item & $\begin{array}{l}\text { Technical } \\
\text { indicators }\end{array}$ & Test results \\
\hline Apparent density, $\left(\mathrm{kg} \cdot \mathrm{m}^{-3}\right)$ & $\leq 40$ & 37.4 \\
Dimensional stability, \% & $\leq 2$ & 1 \\
Compression strength, $\mathrm{kPa}$ & $\geq 150$ & 162 \\
Heat conductivity, $\left[\mathrm{w} /(\mathrm{m} \cdot \mathrm{k})^{-1}\right]$ & $\leq 0.040$ & 0.036 \\
Water absorption, \% & $\leq 2$ & 1.8 \\
Oxygen index, \% & $\geq 30$ & 34.8 \\
\hline
\end{tabular}

\section{Conclusion}

a) The problem of inter-restriction between the flame retardant property and the heat insulation property of the insulation board is solved by preparing thermosetting phenolic resin/ $\mathrm{Al}(\mathrm{OH})_{3}$ flame retardant.

b)The combustibility of PS insulation board after flame retardant coating changes from thermoplasticity to thermosetting property.

c) Performance parameters of molded polystyrene foam board modified by phenolic resin meet the standard requirements; the heat conductivity is $0.033 \sim 0.036 \mathrm{~W} /(\mathrm{m} \bullet \mathrm{K})$, and the combustibility can be effectively improved.

\section{References}

[1]Liangzhi Zou, Li Gao and Jinliang Cui. Application and Analysis of Problems of Extruded PS Insulation Board in Laxiwa Project Construction [J]. Journal of Qinghai University, 2011, 29 (4):48-51.

[2]Yuzhong $\mathrm{Ju}$ and Xuejun Ji. Construction of Plugging-bolt Type Large-module Built-in Cast-in-place External Thermal Insulation System [J]. New Building Materials, 2003 (7):37-39.

[3]Lumin Wang, Daying Zhang and Shupeng Wang. Experimental Study on Waste Po-lystyrene Foam Concrete [J]. Concrete, 2008 (5):103-106.

[4]Zhihui Peng, Mingfeng Chen, Jiahui Peng et al. Study on Waste EPS Exterior Wall Insulation Mortar [J]. Journal of Chongqing Jianzhu University, 2005, 27 (5):101-104.

[5]Xinsheng Zhu, Jianping Dai, Yinqing Li et al. Thermal Degradation of Polystyrene ( $\quad$ I ): Carbonization and Flame-retardant Mechanism [J]. Combustion Science and Technology, 2000, 6 (4): 346-350. 